\title{
REDES URBANAS REGIONAIS E DESENVOLVIMENTO TERRITORIAL: UMA ANÁLISE DO TERRITÓRIO DO NOROESTE DE MINAS NO PERÍODO RECENTE
}

\section{URBAN REGIONAL NETWORKS AND TERRITORIAL DEVELOPMENT: AN ANALYSIS OF "MINAS GERAIS" NORTHWEST TERRITORY IN RECENT YEARS}

\author{
Clesio Marcelino de Jesus \\ Universidade Federal de Uberlândia - Uberlândia - MG - Brasil \\ Soraia Aparecida Cardozo \\ Universidade Federal de Uberlândia - Uberlândia - MG - Brasil
}

\begin{abstract}
Resumo: O presente artigo tem como objetivo mostrar que a constituição de um território rural como recorte para implementação de políticas públicas voltadas para o desenvolvimento necessita considerar a configuração da rede urbana à qual pertencem os municípios que o compõem, com identificação de quais são as relações hierárquicas entre os municípios que conformam o território e se os centros de maior dinamismo irradiam influência para o seu conjunto. Apresenta-se o estudo do caso do Território Noroeste de Minas, no qual foram identificados diversos limites para a implementação das políticas de desenvolvimento territorial. Neste artigo, mostra-se que tais limites se manifestam, em grande medida, pelo fato do território agrupar municípios que possuem diferentes polarizações e estabelecem relações funcionais diferenciadas dentro da rede urbana regional. Constatou-se que, nesse recorte territorial, articulamse diferentes sistemas sócio produtivos e que a delimitação do território não coincide nem mesmo com a regionalização de órgãos públicos estaduais e federais.

Palavras-chave: Território. Desenvolvimento. Rede urbana.
\end{abstract}

Abstract: This article aims to show that the establishment of a rural area as a cutout for implementation of public policies for development needs to consider the configuration of the urban network of the municipalities that compose it, identifying what are the hierarchical relationships between the municipalities that make up the territory and if the most dynamic centers radiate influence to the whole. We present the case study of the Northwest Territory of Minas, where were identified various limits for the implementation of territorial development policies. In this article it is shown that such limits are manifested largely because the territory groups municipalities that have different polarizations and establish differentiated functional relationships within

Redes (St. Cruz Sul, Online), v. 21, n² 2, p. 222 - 244, maio/ago. 2016222 
the regional urban network. It was found that in this territorial clipping are articulated different social production systems and that the delimitation of the territory does not match even with the regionalization of state and federal agencies.

Keywords: Territory. Development. Urban network.

\section{Introdução}

O objetivo deste artigo é mostrar que as dificuldades de implementação das políticas de desenvolvimento territorial no Território Noroeste de Minas devem-se à baixa integração física entre os municípios que o compõem (com falta de acesso viário entre alguns municípios) e, sobretudo, à falta de articulação funcional entre os mesmos. Dessa forma, dentro do recorte territorial oficial, identificouse, no Noroeste de Minas, dois conjuntos de municípios que apresentam características sociais e econômicas semelhantes e maior articulação funcional, elementos essenciais para geração de sinergias e escolha de uma "ideia guia" para promoção do desenvolvimento territorial.

Defende-se, neste artigo, que, embora dinâmica e passível de transformações, a configuração da rede urbana à qual pertencem os municípios que conformam um território é um fator importante a ser considerado nas políticas de desenvolvimento territorial, uma vez que as relações hierárquicas e a influência irradiada a partir dos centros de maior dinamismo influenciam a concertação de interesses e a união em torno de um projeto de desenvolvimento comum.

$O$ entendimento é o de que as políticas públicas voltadas para o desenvolvimento de territórios precisam levar em consideração como se organiza a rede urbana na região, pois, neste sentido, pode-se delimitar os fluxos que se estabelecem entre os municípios envolvidos, as funções que eles exercem, e, se além da contiguidade física, há articulação funcional entre os mesmos. Mostrar-se-á que no caso do território Noroeste de Minas, sua formação enquanto um espaço alvo de políticas públicas voltadas para o desenvolvimento, articulou municípios que têm pequena articulação funcional, a qual, algumas vezes, é muito mais representativa com municípios que estão fora do recorte do território institucional.

Esta abordagem de ressaltar a importância de se entender a dinâmica das redes urbanas para se tratar inclusive do desenvolvimento territorial rural, justifica-se porque o desenvolvimento tem que ser 
interpretado e planejado de forma integrada, superando a setorização rural versus urbano, visto que as atividades rurais e urbanas apresentam importantes interligações. Nesse sentido, as políticas públicas que auxiliarão na promoção do desenvolvimento não podem se restringir ao aspecto setorial e devem ter um caráter territorial, que transcenda o recorte administrativo e levem em consideração a articulação funcional dos municípios.

A elaboração deste artigo é fruto de uma pesquisa realizada pelos autores no Território Noroeste de Minas, com apoio do Ministério do Desenvolvimento Agrário - MDA e do Conselho Nacional de Desenvolvimento Científico e Tecnológico - CNPq, que permitiu a inserção dos pesquisadores no território para realização de pesquisa de campo e participação das reuniões do colegiado. Assim, os pesquisadores tiveram, nos anos de 2010 a 2013 , contato direto com os atores sociais que estão envolvidos na definição de quais são as demandas territoriais. Essa experiência permitiu a elaboração de hipóteses explicativas para a dificuldade de sinergia e bom funcionamento daquele espaço enquanto um território, alvo de políticas governamentais. Com base na experiência adquirida com a referida pesquisa, apresenta-se aqui uma hipótese de que o processo de formação do território não levou em consideração as relações funcionais entre os municípios e que isso consiste em um dos entraves para a implementação da política de desenvolvimento territorial. Ademais, percebeu-se que não foi considerada a dinâmica socioeconômica bastante heterogênea entre os municípios que compõem o recorte territorial.

Para o presente trabalho, recorreu-se às Regiões de Influência das Cidades - REGIC 2007, do Instituto Brasileiro de Geografia e Estatística IBGE, para verificar quais são as relações funcionais entre os municípios que compõem o território, além da análise de dados que retratem a realidade econômica e social dos municípios. Essas informações permitiram concluir que há diferentes realidades econômicas e sociais dentro do território e que elas refletem as diferentes relações funcionais entre os municípios.

Além desta introdução e das considerações finais, o artigo apresenta outras três seções. Na primeira seção, são apresentados breves apontamentos teóricos para fazer as intermediações necessárias 
entre o desenvolvimento territorial e as redes urbanas regionais. $\mathrm{Na}$ segunda seção mostrar-se-á quais são as áreas de influência sobre os municípios que compõem o Território Noroeste de Minas com o intuito de evidenciar que dentro do território existem conjuntos de municípios que são polarizados por diferentes cidades. Por fim, na terceira seção, é feita análise do conjunto de dados socioeconômicos que permite demonstrar pelo menos duas dinâmicas econômicas e sociais distintas no Território.

\section{Desenvolvimento Territorial e Rede Urbana: breves apontamentos}

As estratégias de desenvolvimento territorial se propõem a superar a dicotomia rural versus urbano à medida que não defendem, necessariamente, a identidade entre rural e atividades agropecuárias (VEIGA, 2002 e ORTEGA, 2008). Ademais, a noção de contiguidade e relação funcional entre os municípios são elementos essenciais para se pensar políticas públicas voltadas para o território. Nesse sentido, este artigo propõe-se a apresentar intermediações necessárias entre esse debate e a conformação das redes urbanas, à medida que os sistemas urbanos se aglomeram, com alta ou baixa intensidade, estabelecendo fluxos que revelam como os sistemas produtivos se organizam espacialmente e como os centros urbanos, dentro dessa organicidade, assumem funções específicas.

Diversos estudos têm chamado a atenção para as transformações que o meio rural vem passando nas últimas décadas e, dentre elas, pode-se destacar a valorização crescente de atividades não agrícolas no espaço rural. Além disso, outro aspecto relevante destacado consiste na necessidade de que as políticas públicas abranjam, de forma integrada, o campo e a cidade, pois como bem enfatiza Jesus (2013, p. 76), "ao entender que a promoção do desenvolvimento rural necessita de uma perspectiva espacial, é preciso ficar claro que o foco das ações e políticas envolve toda a população de um recorte, o território, ou seja, no campo e na cidade de forma integrada". Nesse sentido, há uma ênfase na necessidade de surgimento de uma institucionalidade intermunicipal que viabilize não apenas a implementação das políticas de desenvolvimento, mas, sobretudo, a elaboração de tais políticas com base nas necessidades e prioridades destacadas pela coletividade. 
Sobre a diversificação das atividades rurais, Jesus (2013, p. 72) enfatiza que

o meio rural tem passado por transformações recentes em todo o mundo. A aplicação do pacote tecnológico da "revolução verde" possibilitou ampliar a especialização da atividade agropecuária em diversos setores, de forma que ela está cada vez mais integrada à indústria, constituindo os complexos agroindustriais. (...) Essas atividades não-agropecuárias são consideradas, por vezes, como de caráter urbano e têm constituído um importante mercado de bens e serviços, gerando emprego e renda para o mundo rural. Assim, não é fácil traçar uma linha separando o que sejam atividades típicas do mundo rural daquelas desenvolvidas nas cidades.

As propostas de desenvolvimento passam a ser direcionadas, sobretudo, para as áreas consideradas deprimidas, que não foram beneficiadas pelo crescimento econômico até então, principalmente o desenvolvimento local e, mais recentemente, o desenvolvimento territorial, que tem despertado o interesse de instituições públicas e privadas e de teóricos de diferentes áreas do conhecimento. Segundo Guimarães Neto (2010, p. 69)

(...) deve-se ser mencionado o fato de que a emergência dessa abordagem territorial do desenvolvimento rural tem sua origem, também, no reconhecimento da ocorrência de novas dinâmicas espaciais, a exemplo de uma aproximação do rural com o urbano e a constatação de que a industrialização e a modernização agrícola não constituiriam elementos suficientes para a efetiva promoção do desenvolvimento rural.

Nesse sentido, a política de desenvolvimento territorial no Brasil apresentou uma importante inflexão em 2003, quando, de fato, a noção de desenvolvimento rural deixou de estar conectada apenas a aspectos setoriais identificados com a produção agropecuária e passou a enfatizar as relações, sobretudo, de complementaridade entre o rural e o urbano (ECHEVERRI, 2010). Segundo o autor (p. 90), na política de desenvolvimento territorial

podem ser destacados os seguintes aspectos chaves: primeiro, a integração do urbano e do rural num mesmo espaço geográfico, que define a integralidade das relações funcionais, 
econômicas e sociais entre os espaços de baixa densidade populacional e os núcleos ou centros com os quais se relacionam. Segundo, o caráter multidimensional que introduz um equilíbrio com a visão predominantemente econômica que tem prevalecido nas concepções mais tradicionais de desenvolvimento rural e que introduz os aspectos sociais, ambientais, políticos e culturais como essenciais na construção das ações e programas. Terceiro, a introdução do tema da identidade e sua relação com a coesão social.

Trata-se, portanto, de um passo importante para se dar um tratamento territorial ao desenvolvimento rural, ou seja, a intervenção política se dará de forma multiescalar, transcendendo as divisões político-administrativas e, desta forma, as políticas públicas voltadas para o rural serão também, de todo modo, políticas regionais. Ou seja, não são políticas setoriais, voltadas exclusivamente para atividades agropecuárias, não são apenas as atividades rurais que serão alvo das intervenções públicas em virtude das relações de complementaridade entre o rural e o urbano, como por exemplo as complementaridades que se estabelecem com os fluxos diários que se dão entre campo e cidade, inclusive o fluxo de pessoas.

Nesse sentido, segundo Ortega (2008, p.53),

As recentes políticas públicas de desenvolvimento rural, que
usam o critério territorial em sua implementação, fazem-no
com base no incentivo da constituição de territórios-zona, ou
seja, em espaços contínuos. Apreendemos, portanto, os
territórios, como espaços delimitados, nos quais se praticam
diferentes tipos de intercâmbio em seu interior (inclusive de
poder) e com o exterior (com outros territórios, localidades,
espaços regionais ou nacionais e com a comunidade
internacional), de uma perspectiva de competitividade territorial
que combina as dimensões econômicas, social, ambiental e
política.

As políticas voltadas para o desenvolvimento territorial buscam superar a lógica autônoma, endógena, fragmentada e "espontânea" de pensar o local como o elemento central para o desenvolvimento dos territórios deprimidos, por meio de uma lógica mais ampla e que rompe com vários desses pressupostos. Assim, constrói-se uma proposta de desenvolvimento territorial que leva em consideração as especificidades 
locais, o desenvolvimento econômico desigual, a participação da sociedade, a maior atuação do Estado e os novos modelos de desenvolvimento.

No que se refere à evolução da política territorial, em 2007, houve a implementação do Território da Cidadania, que, como destaca Echeverri (2010, p. 105).

Os objetivos do Programa se relacionam mais diretamente com as metas de superação de pobreza e se identificam como uma estratégia diferenciada para atenção às populações mais vulneráveis, tanto em termos regionais, como de grupo social. Especificamente, é proposta a superação da pobreza e a geração de trabalho e renda por meio da inclusão produtiva dos mais pobres, a integração das políticas públicas em um marco de planejamento territorial, ampliação dos mecanismos de participação social e a universalização da oferta de programas de cidadania, ou seja, de reconhecimento e garantia de direitos.

A política territorial encontra respaldo teórico, sendo tema recorrente no meio acadêmico. Jesus (2013) ressalta que as análises que utilizam o enfoque metodológico territorial são inúmeras e de vários aportes teóricos. Ademais, o autor destaca que a análise territorial ultrapassa os aspectos físicos da noção do território e incorporam a noção de conexão, articulação e dinâmica socioespacial (p. 69).

A abordagem territorial enfatiza a capacidade de organização da sociedade em torno de interesses comuns como sendo o aspecto fundamental dos processos de desenvolvimento. Dessa forma, a concertação de interesses aparece como um dos elos fundamentais para a elaboração da política de desenvolvimento territorial, à medida que a sociedade, de acordo com esse enfoque, tem poder de influenciar a elaboração das políticas públicas. Tem-se, portanto, o entendimento do território como algo dinâmico, vivo, constituído de um conjunto de atores sociais que interagem em torno de projetos comuns, normalmente, frutos de uma ação política. O objetivo é a união de um conjunto de municípios em torno de um projeto de desenvolvimento territorial consolidando a formação de arranjos intermunicipais capazes de promover o seu desenvolvimento.

Nesse contexto, a formação dos projetos comuns e da concertação de interesses depende da união entre municípios em torno 
de um projeto de desenvolvimento comum, e essa união é a base para formação dos projetos delineados pelos atores sociais do território. Assim, esse critério não foi privilegiado na definição do Território do Noroeste de Minas.

Para Guimarães Neto (2010, p. 67), as ações do planejamento regional precisam "evitar ação isolada, parcial ou incompleta de territórios e regiões individuais, desarticuladas do seu contexto mais geral". Isso reforça a proposta de que, para a delimitação de um território, é imprescindível que os municípios estejam dentro de uma mesma rede urbana, pois, dessa forma, estabelece-se não apenas a contiguidade espacial, mas, sobretudo, a dependência funcional entre os municípios que conformam o território. Há a necessidade de que haja, minimamente, interdependência econômica para que sejam moldados os interesses comuns dentro do território e, nesse sentido, há a necessidade de se fazer a intermediação entre o aporte territorial e a configuração de redes urbanas. Segundo Corrêa (1988, p. 119, apud IPEA, 2001, p. 25), a rede urbana é a forma espacial em que se cria um "conjunto funcionalmente articulado de centros hierarquizados e suas diferentes manifestações em termos de forças de suas unidades, constituindo-se uma estrutura territorial onde se dá a criação, apropriação e circulação do valor excedente".

Esse conjunto funcionalmente articulado é formado por municípios que exercem diferentes graus de centralidade, o que se manifesta de forma hierarquizada, e a centralidade está diretamente relacionada à forma como determinado centro urbano estrutura uma área de influência, através da abrangência regional do fluxo de pessoas em busca de bens e serviços.

Os sistemas urbano-regionais compreendem sistemas
territoriais organizados a partir de metrópoles (globais,
nacionais ou regionais) e centros regionais que possuem
encadeamento funcional entre os diversos níveis de influência,
seja recíproco, isto é, entre cidades do mesmo nível de
polarização, seja hierárquico, dos níveis superiores para os
inferiores". (MOTTA; AJARA, 2001, p. 13).

A análise acerca da estruturação da rede urbana se baseia no estudo das "porções do espaço submetidas à influência de centros urbanos, cujos fluxos de pessoas, mercadorias e informações permitem 
a conformação de estruturas territoriais relativamente estáveis no decorrer do tempo" (IPEA, 2001, p. 13). De tal maneira, destaca-se que os critérios de contiguidade espacial e dependência funcional, que são ideias fortes para o estudo da rede urbana e para o entendimento da dinâmica regional do país, são extremamente importantes para o estudo de territórios com finalidades acadêmicas e, sobretudo, para a delimitação dos territórios e para a efetivação das políticas territoriais.

Cada centro, independente de seu tamanho, possui funções específicas dentro da rede urbana nacional, segundo IPEA (2001, p. 14).

\begin{abstract}
Os diversos tipos de aglomeração e integração espacial existentes entre os centros urbanos, ao mesmo tempo que expressam sua inserção e o papel desempenhado na estrutura produtiva, refletem os diversos arranjos possíveis entre as duas faces do padrão de urbanização e engendram uma configuração espacial peculiar para cada segmento da rede urbana.
\end{abstract}

Dessa forma, cada município, independente de seu tamanho, participa de um ou mais "circuitos espaciais de produção, produzindo, distribuindo ou apenas consumindo bens, serviços e informações". Os municípios estabelecem, portanto, funções específicas dentro da rede urbana, gerando vínculos funcionais mais fortes, que se expressam nos fluxos de bens, serviços, pessoas, com outros municípios, principalmente com aqueles que conformam um mesmo sistema produtivo.

Dois conceitos que norteiam a análise da estruturação da rede urbana são contiguidade espacial e dependência funcional. Nessa perspectiva, a articulação que se dá entre os municípios não é apenas espacial, mas, sobretudo, de fluxos que conformam uma articulação em que os centros urbanos estabelecem diferentes funções. Tais fluxos são mais intensos em regiões metropolitanas, mas também são relativamente importantes em áreas em que se concentram municípios de menor porte e, no caso do Noroeste Minas, como mostra figura 1, há diferentes conjuntos de municípios que são polarizados por diferentes centros regionais ou sub-regionais.

Ademais, o conceito de desenvolvimento territorial compreende a noção de conciliação de interesses, mas no Território Noroeste de Minas os interesses são, muitas vezes, conflitantes, à medida que convivem, 
no mesmo território, um conjunto de municípios com uma agricultura mais moderna, como café e grãos, voltados para a exportação e com significativo grau de tecnificação; e uma agricultura de pequeno porte com presença significativa da produção para o autoconsumo e para o mercado interno. Ao mesmo tempo, num mesmo território, identifica-se duas realidades bastante distintas em termos socioeconômicos e que apresentam demandas diferenciadas em um único projeto de desenvolvimento. Os municípios se articulam de forma diferente inclusive no que se refere a gestão de suas autarquias estaduais e empresas públicas, que são recorte definidos pela unidade da federação, o que cria uma outra articulação entre os municípios, que não coincide com o recorte territorial.

Aliado a essa situação, no Território Noroeste de Minas existem grupos de municípios que estão sob a influência de distintos centros regionais, voltados para diferentes regiões do país, o que reforça a proposta de que é difícil construir convergência de interesses no território, como será visto na próxima seção.

\section{Análise das diferentes regiões de influência sobre o Território Noroeste de Minas}

O Território Noroeste de Minas (Figura 1) foi criado em 2003 e homologado em 2004, ainda no início da execução do Programa de Desenvolvimento Territorial levado a termo pela Secretaria de Desenvolvimento Territorial do Ministério do Desenvolvimento Agrário SDT/MDA. Nesse contexto, dezenove municípios deveriam participar das ações do Território: Arinos, Bonfinópolis de Minas, Brasilândia de Minas, Dom Bosco, Formoso, Guarda-Mor, João Pinheiro, Lagamar, Lagoa Grande, Natalândia, Paracatu, Presidente Olegário, Riachinho, Santa Fé de Minas, São Gonçalo do Abaeté, Uruana de Minas, Urucuia, Varjão de Minas e Vazante. Em fevereiro de 2008, o Território foi incluído em outro programa do governo federal, conforme Decreto de 25 de fevereiro de 2008, publicado no Diário Oficial da União de 26/02/2008, transformando-o no Território da Cidadania Noroeste de Minas, o que incorporou mais três municípios: Chapada Gaúcha, Pintópolis e São Romão (PTDRS, 2010). 
Conforme foi demonstrado na revisão teórica, na delimitação de um território é fundamental que as cidades sedes municipais estejam dentro de uma mesma rede urbana, estabelecendo contiguidade espacial e a dependência funcional. Entretanto, a constituição do Território Noroeste de Minas, com 22 municípios, compreende cidades sob influência de três maiores centros (rede de influências), com sentidos e fluxos divergentes e que não se complementam, conforme está representado na Figura 2, tomando como referência a Região de Influências das Cidades 2007 (REGIC, 2008).

Figura 1. Municípios que compõem o Território Noroeste de Minas

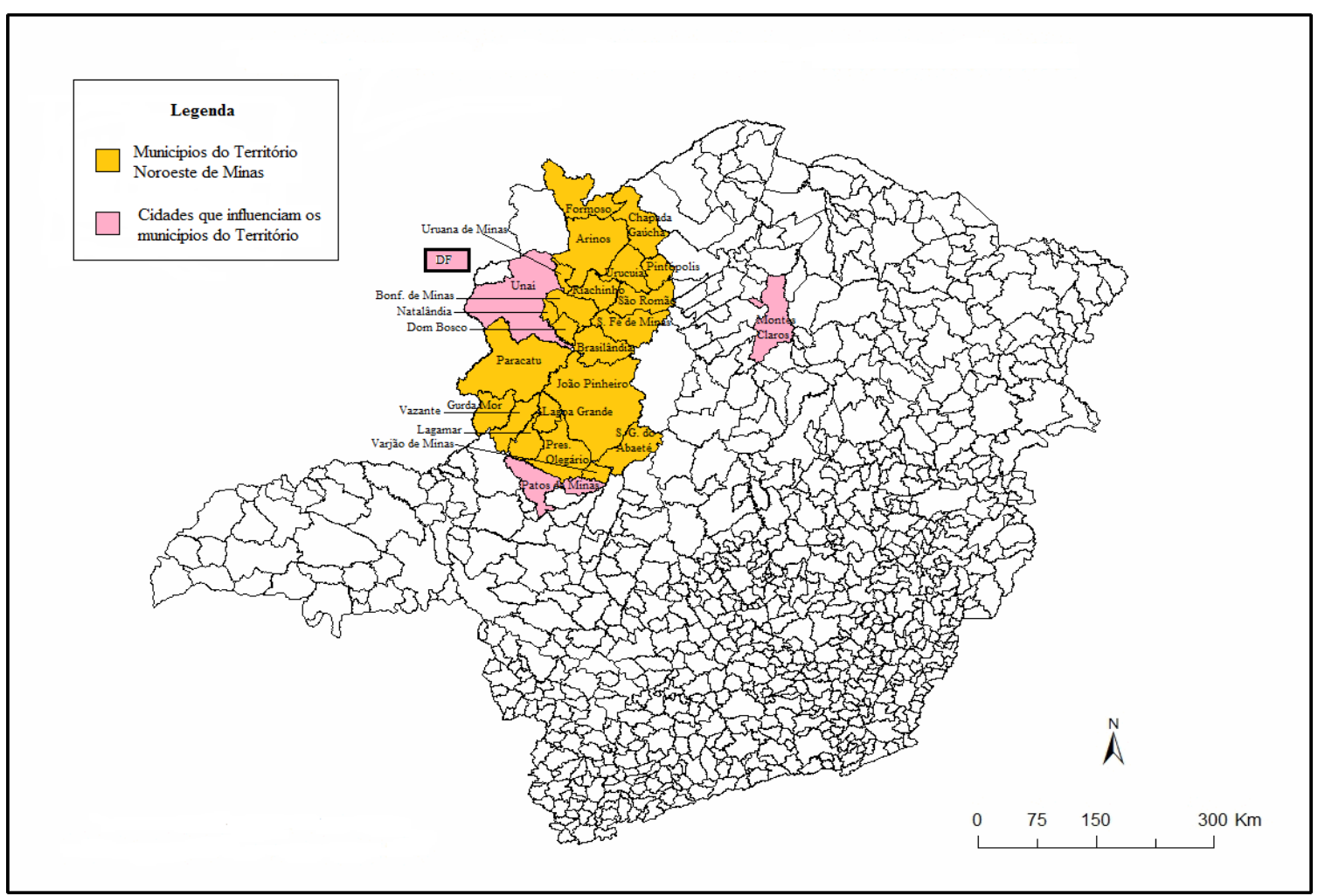

Fonte: Elaborado pelos autores com base no IBGE e Ministério do Desenvolvimento Agrário - MDA.

A primeira rede de influência reúne nove sedes municipais do território, sete classificadas como centros locais (Lagamar, Lagoa Grande, Presidente Olegário, São Gonçalo do Abaeté, Varjão de Minas, Brasilândia e Guarda-Mor), e duas como centros de zona B (João Pinheiro e Vazante), todas sob influência de Patos de Minas que está fora do recorte territorial (Figura 1). Patos de Minas, por sua vez, está 
sob influência de Uberlândia e Uberaba, ambas sob influência de São Paulo. Uberaba também está sob a influência de Belo Horizonte.

Deve-se destacar que, na atualidade, a influência de metrópoles e centros regionais dentro da rede urbana nacional se estabelece, de forma bastante significativa, através do meio técnico científico informacional. Novos conteúdos, além da circulação de produtos, insumos e dinheiro, surgem na organização do território nacional. A informação e as finanças ampliam sua importância na formação do espaço econômico nacional, tornando-o mais fluido e passível de mudanças (SANTOS, 2001). O capital intensifica a expansão geográfica, "anula o espaço pelo tempo", fazendo com que a distância seja menos importante que a velocidade da circulação da mercadoria. Como ressalta Brandão (2007, p. 52), "surgem novas interdependências, vínculos mercantis e não mercantis, setoriais e territoriais, que redefinem circuitos produtivos regionais/locais e re(criam) novos usos das heterogeneidades espaciais pelo capital". 
Figura 2. Região de Influência das Cidades sobre os Municípios do Território Noroeste de Minas

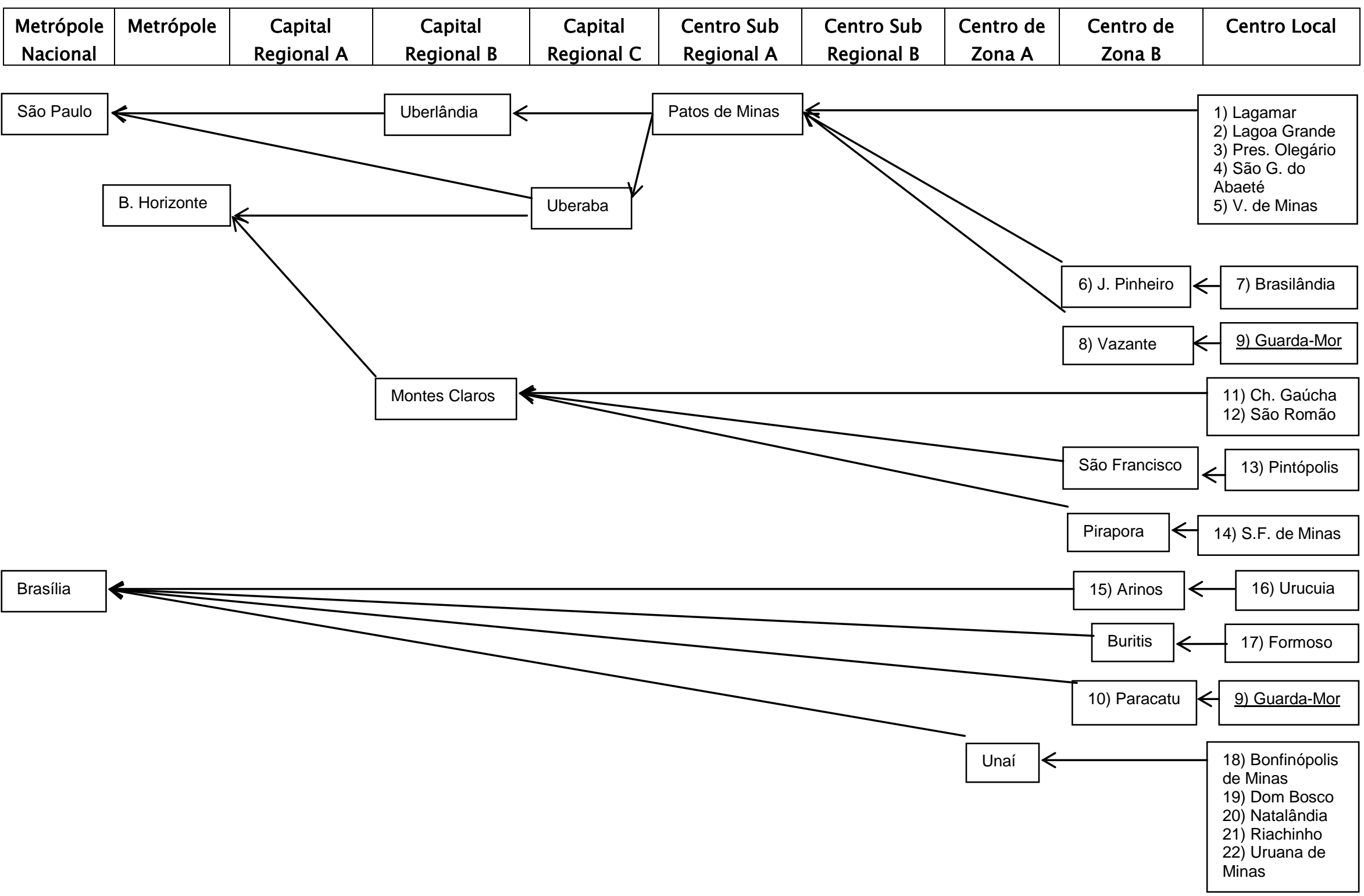

Redes (St. Cruz Sul, Online), v. 21, nº 2, p. 222 - 244, maio/ago. 2016234 
Redes Urbanas Regionais e Desenvolvimento Territorial: uma análise do território...

Fonte: Elaborado pelos autores com base na Região de Influências das Cidades 2007 - (IBGE, 2008). 
A influência de Patos de Minas sobre esses nove municípios se deve a um conjunto de fatores. Primeiramente, o porte do município, considerado pela REGIC um centro sub-regional A, localizado ao sul do território, na mesma direção dos nove municípios supracitados, dos quais, quatro fazem limite fronteiriço. Em segundo lugar, vem o canal de transportes, rodovias que cortam os nove municípios e tem como principal direção Patos de Minas, um entroncamento rodoviário que permite seguir para outras cidades do estado ou do país. Em terceiro lugar, Patos de Minas foi se consolidando com um importante centro comercial para a região do Alto Paranaíba e parte do Vale do Paracatu, envolvendo os nove municípios e outros do território. Por fim, pode ser apontado o conjunto de órgãos/autarquias estaduais e até federais que estão presentes em Patos de Minas e mantêm área de atuação sobre parte dos municípios do território, que em muitos casos, extrapolam os nove municípios.

Sendo assim, vários fluxos têm como destino a cidade de Patos de Minas. No caso da atividade econômica, a agropecuária, por meio da produção de café, grãos e leite, está presente nos nove municípios e também é muito forte no Município de Paracatu, sede do território. Patos de Minas polariza um conjunto de atividades econômicas, tanto pela presença de cooperativas leiteiras que atuam sobre esses municípios quanto pela atuação de grandes grupos produtores de grãos e armazéns que realizam suas operações a partir dessa cidade.

Vários órgãos públicos que ofertam serviços estaduais estão sediados em Patos de Minas e possuem atuação regional. Essa atuação é voltada para parte do Vale do Paracatu, como acontece com a Empresa de Assistência Técnica e Extensão Rural do Estado de Minas Gerais EMATER. A regional de Patos de Minas é a responsável por escritórios em sete das nove cidades; o Instituto Estadual de Florestas - IEF, a partir da regional de Patos de Minas, é o responsável por escritórios em quatro das nove cidades e o Instituto Mineiro de Agropecuária - IMA, tem organização semelhante; enquanto o Hospital Regional recebe pacientes dos municípios citados e de outros municípios do território. Ao mesmo tempo, a cidade de Patos de Minas é um importante centro de educação regional, destino de estudantes, principalmente universitários, que se deslocam diariamente, por meio de ônibus, de sete dentre os nove municípios do território. Assim, é comum membros do colegiado dessa 
parte do território reclamarem que possuem maiores vínculos com a cidade de Patos de Minas do que Paracatu, que atualmente é sede do território.

Varjão de Minas e São Gonçalo do Abaeté, além de estarem vinculados a Patos de Minas em várias atividades, estão distantes de Paracatu e de outras cidades do território. Até a sede é necessário o deslocamento superior a 240 quilômetros (GUIA RODOVIÁRIO, 2010), o que dificulta a participação dos membros no colegiado territorial, ao passo que estão numa distância inferior a 100 quilômetros de Patos de Minas. No período que a Células de Acompanhamento e Informação CAll esteve acompanhando as atividades do Colegiado, foi verificado que estes municípios eram pouco representados, São Gonçalo do Abaeté mantinha como representante apenas a Prefeitura Municipal e Varjão de Minas não participava.

Nesse sentido, fica clara a articulação mais intensa de municípios que estão dentro do território com municípios que estão fora do território e exercem grande capacidade de polarização.

A segunda rede de influência abrange quatro municípios do território, todos classificados como centros locais e estão sob a influência da cidade de Montes Claros, considerada uma capital regional B pela REGIC (2008), que também está fora do recorte territorial (Figura 1) e possui outra dinâmica regional que, por sua vez está sob a influência de Belo Horizonte, a capital do Estado. Desses quatro municípios, dois estão sob a influência direta (Chapada Gaúcha e São Romão), e dois estão sob a influência indireta, ou seja, são polarizados primeiramente por centros de zona B (Pintópolis à cidade de São Francisco e Santa Fé de Minas à Cidade de Pirapora, ambas não fazem parte do território) (Figura 2).

A influência de Montes Claros sobre esses quatro municípios se deve a um conjunto de fatores. Primeiramente, eles estão localizados na parte Nordeste do Território, mais próximos à cidade de Montes Claros que a Paracatu. Ao mesmo tempo, os municípios de Pintópolis e São Romão estão ligados por rodovias pavimentadas por asfalto à cidade de Montes Claros e por rodovias não pavimentadas (de terra), quase

\footnotetext{
1 Células de Acompanhamento e Informação são unidades administrativas com funções de coletar e registrar nas bases do sistema, sobretudo, dados relacionados com os seus primeiros cinco componentes (territórios, atores, planos, projetos e colegiados).
} 
sempre mal conservadas, a outros municípios do Território Noroeste de Minas, o que amplia os vínculos com a região Norte de Minas, com deslocamento de pessoas, produção e finanças para aquelas cidades, destacando Montes Claros. No caso de Chapada Gaúcha e Santa Fé de Minas, só recentemente esses municípios passaram a ter ligações por rodovias asfaltadas aos outros municípios do Noroeste. Isso pode levar a uma maior integração, pois as rodovias para Montes Claros para esses dois municípios ainda são por terra, necessitando atravessar grandes rios por Balsa.

Tanto Pintópolis como São Romão não possuem representantes no Colegiado², e a principal alegação dos membros que foram convidados e não participam é o problema de deslocamento e a falta de vinculação com os municípios do Noroeste de Minas, principalmente, Paracatu (FERNANDES FILHO et al., 2014).

Nesse conjunto de municípios, o maior fluxo de pessoas está no sentido do Norte de Minas - São Francisco, Januária e Montes Claros -, com a presença de importantes linhas de ônibus, assim como alguns serviços do estado que possuem órgãos com atuação regional estão sediados em Montes Claros e outras cidades do Norte de Minas. Como acontece com órgãos como a EMATER, o Município de Chapada Gaúcha está vinculado à regional de Januária. Já Pintópolis, Santa Fé de Minas, São Romão e Urucuia estão vinculados à cidade de São Francisco. Situação análoga ocorre com o Instituto Estadual de Florestas - IEF e Instituto do Meio Ambiente - IMA. Ainda é importante ressaltar que Montes Claros é o destino de muitos pacientes para tratamentos de saúde por conta de seus hospitais com atuação regional. Assim, é comum membros do colegiado dessa parte do território reclamarem que possuem maiores vínculos com a cidade de Montes Claros que Paracatu.

A terceira rede de influência reúne os outros nove municípios que estão sob influência de Brasília, considerada pela REGIC 2007 uma metrópole nacional que também está fora do território (Figura 1). Conforme representação na Figura 2, desses nove municípios, três estão sob influência direta de Brasília: Arinos, considerado um centro zona B

2 Colegiados Territoriais são "formados por representantes de organizações da sociedade civil e dos poderes públicos que atuam no território" e "constituem-se em um espaço de orquestração do desenvolvimento sustentável e de quais os caminhos e estratégias mais adequadas para promovê-lo" (SDT/MDA, 2010). 
que polariza Urucuia (cidade local) e Paracatu, também considerado um centro zona B, que polariza Guarda-Mor (que, por sua vez, está sob influência de Patos de Minas). O quarto município é Formoso (cidade local) que é influenciada primeiramente pela cidade de Buritis, um Centro de Zona B que não faz parte do Território Noroeste de Minas. Enquanto Bonfinópolis de Minas, Dom Bosco, Natalândia, Riachinho e Uruana de Minas, denominada de cidades locais, estão sob influência da cidade de Unaí (centro zona A) que não faz parte do Território e também influencia Arinos, Urucuia e Formoso, a exceção é Paracatu dentre os nove municípios.

A polarização desses nove municípios à cidade de Brasília se deve a um conjunto de fatores. Primeiramente, podem ser apontadas as rodovias que cortam os municípios em direção à capital federal juntamente com a proximidade e os serviços que a mesma oferta, especialmente os de saúde e educação. Em seguida, está o peso populacional de Brasília que se constitui num importante mercado consumidor de produtos agrícolas para esse conjunto de municípios, especialmente hortifrutigranjeiros e grãos, além da cidade ser um importante centro comercial para as populações desses pequenos municípios.

Ainda há influência direta de Brasília sobre esse conjunto de municípios na dinâmica populacional, seja pelo fluxo de trabalhadores que se deslocam para trabalhar na cidade e seu entorno ao longo da semana e retornam aos seus municípios nos fins de semana, seja pela presença de sítios/chácaras, casas de campo de pessoas que vivem em Brasília e buscam refúgio nesses municípios.

A cidade de Unaí influencia esses nove municípios em vários aspectos. No caso da EMATER, a Regional Unaí é a responsável por oito dos nove municípios (www.emater.mg.gov.br). Inclusive é o escritório da regional de Unaí que libera o técnico para acompanhar as reuniões do Colegiado Territorial. O escritório regional do IEF de Unaí é o responsável pelos nove municípios e mais cinco municípios do território. A cidade também é um importante centro de educação regional, destino de estudantes, principalmente, universitários que se deslocam diariamente, por meio de ônibus, de cinco dentre os nove municípios e oferta serviços de saúde para a maioria dos nove municípios. 
A dinâmica econômica de alguns municípios é próxima e está ligada diretamente a cidade de Unaí. No caso da produção agropecuária, a principal chapada produtora de grãos é integrada, envolvendo parte dos municípios de Natalândia, Dom Bosco, Bonfinópolis de Minas, Uruana de Minas, Arinos e Buritis e Unaí, que não fazem parte do território. Esta atividade está diretamente ligada à cidade de Unaí, um importante centro comercial na produção agropecuária.

Ao analisar-se o fluxo de deslocamentos das pessoas ocupadas calculados pelo IBGE a partir do Censo Demográfico de 2010, reforça-se o argumento de que existem três redes urbanas principais com sentidos e fluxos. No Anexo 1, os dados da matriz de deslocamento das pessoas ocupadas demostram que os nove municípios sob influência de Brasília e Unaí tem como principal destino as respectivas cidades e em menor grau cidades do entorno de Brasília, sendo que o deslocamento para Paracatu é pouco expressivo e ocorre em seis municípios. Somente Brasilândia de Minas apresenta um fluxo significativo para João Pinheiro em função da presença de uma usina de açúcar e álcool.

No deslocamento dos quatro municípios que são polarizados principalmente por cidades do Norte de Minas, com destaque para Montes Claros, apenas Chapada Gaúcha apresentou pequeno deslocamento em direção a Paracatu. No geral, o deslocamento é diversificado em direção às cidades do Norte de Minas, Brasília e cidades do entorno, com baixo deslocamento interno. Os nove municípios que são polarizados principalmente por Patos de Minas apresentam maior deslocamento entre as próprias cidades, especialmente, as duas maiores: João Pinheiro e Paracatu e o deslocamento para outras cidades próximas e no sentido da zona de influência de Patos de Minas, destacando Coromandel e Uberlândia.

Portanto, considerando-se que existem três principais áreas de influência distintas, fica evidente que trata-se de uma rede urbana pouco densa entre os municípios que compõe o Território Noroeste de Minas. Isso exige repensar o recorte territorial, pois os municípios estabelecem fortes relações funcionais (saúde, educação, produção, comércio e serviços) com outras cidades que estão fora do recorte, o que dificulta configurar um projeto comum. Logo, é complexo constituir um território homogêneo, pois esses três vetores polarizam e influenciam o território de diferentes formas. 


\section{A dinâmica socioeconômica do Território Noroeste de Minas}

Além de estar sob três principais regiões de influência distintas, outros indicadores socioeconômicos reforçam a ideia de diversidade no Território Noroeste de Minas, o que permite caracterizá-lo em dimensões distintas (dois subterritórios distintos). Analisando os dados, é possível identificar um conjunto de municípios com sérias carências e baixos indicadores sociais que estão localizados no Vale do Rio Urucuia, constituído pelos municípios que estão na área de influência de Brasília e Montes Claros (com exceção de Paracatu); e outro conjunto de municípios do Território, em um patamar acima, mas não em uma situação excelente, que fazem parte da Bacia do Vale do Rio Paracatu e são influenciados por Patos de Minas (com inclusão Paracatu). Essa divisão, na prática, já ocorre no Território Noroeste de Minas, inclusive com proposição de divisão do território proposta pelo Colegiado Territorial a SDT/MDA, situação que nos motivou analisar tal divisão.

A Tabela 1 sintetiza informações populacionais do Território Noroeste de Minas distribuídos pelos dois conjuntos de municípios. Como pode ser observado, o Vale do Urucuia reúne 12 municípios, com baixa população e peso significativo da população no meio rural, média de $43,5 \%$, enquanto o estado possui $14,7 \%$. O número de habitantes oscila entre 3.235 no município de Uruana de Minas a 17.674 em Arinos, resultando num perfil socioeconômico relativamente próximo entre os municípios. De modo geral, o recorte reúne municípios com grandes dimensões, o que resulta em baixíssima densidade demográfica, apenas 3,72 habitantes por $\mathrm{km}^{2}$. São $25.795,30 \mathrm{~km}^{2}$ para 95.916 habitantes, dos quais 41.718 vivem no campo.

Tabela 1. Informações populacionais dos municípios do Território Noroeste de Minas 


\begin{tabular}{|c|c|c|c|c|c|c|c|c|c|c|}
\hline & \multirow{3}{*}{ Municípios } & \multicolumn{4}{|c|}{ População 2010} & \multirow{2}{*}{\multicolumn{3}{|c|}{$\begin{array}{c}\text { Taxa Anual de } \\
\text { Crescimento } 00-10\end{array}$}} & \multirow{3}{*}{$\begin{array}{c}\text { Área total do } \\
\text { município }\end{array}$} & \multirow{3}{*}{$\begin{array}{c}\text { Habitantes } \\
\text { por km }{ }^{2}\end{array}$} \\
\hline & & \multirow{2}{*}{ Total } & \multirow{2}{*}{$\begin{array}{c}\text { Urbana } \\
\text { Total }\end{array}$} & \multicolumn{2}{|c|}{ Rural } & & & & & \\
\hline & & & & Total & $\%$ & Total & \begin{tabular}{|l|l|} 
Urbana \\
\end{tabular} & Rural & & \\
\hline \multirow{12}{*}{$\begin{array}{l}\text { Vale do } \\
\text { Urucuia }\end{array}$} & Arinos & 17.674 & 10.854 & 6.820 & $38,6 \%$ & $-0,02 \%$ & $0,69 \%$ & $-1,04 \%$ & $5.338,50$ & 3,31 \\
\hline & Bonfinópolis de Minas & 5.865 & 4.137 & 1.728 & $29,5 \%$ & $-0,94 \%$ & $-0,16 \%$ & $-2,57 \%$ & $1.825,80$ & 3,21 \\
\hline & Chapada Gaúcha & 10.805 & 5.761 & 5.044 & $46,7 \%$ & $4,04 \%$ & $6,46 \%$ & $1,87 \%$ & $2.477,20$ & 4,36 \\
\hline & Dom Bosco & 3.814 & 2.052 & 1.762 & $46,2 \%$ & $-0,61 \%$ & $0,16 \%$ & $-1,43 \%$ & 824,50 & 4,63 \\
\hline & Formoso & 8.177 & 5.173 & 3.004 & $36,7 \%$ & $2,29 \%$ & $4,26 \%$ & $-0,36 \%$ & $3.833,40$ & 2,13 \\
\hline & Natalândia & 3.280 & 2.471 & 809 & $24,7 \%$ & $-0,04 \%$ & $0,46 \%$ & $-1,42 \%$ & 473,00 & 6,93 \\
\hline & Pintópolis & 7.211 & 2.532 & 4.679 & $64,9 \%$ & $0,37 \%$ & $1,40 \%$ & $-0,14 \%$ & $1.236,80$ & 5,83 \\
\hline & Riachinho & 8.007 & 4.435 & 3.572 & $44,6 \%$ & $0,04 \%$ & $1,30 \%$ & $-1,31 \%$ & $1.739,40$ & 4,60 \\
\hline & Santa Fé de Minas & 3.968 & 2.291 & 1.677 & $42,3 \%$ & $-0,55 \%$ & $1,54 \%$ & $-2,79 \%$ & $2.926,50$ & 1,36 \\
\hline & São Romão & 10.276 & 6.469 & 3.807 & $37,0 \%$ & $2,82 \%$ & $2,27 \%$ & $3,83 \%$ & $2.444,80$ & 4,20 \\
\hline & Uruana de Minas & 3.235 & 1.818 & 1.417 & $43,8 \%$ & $-0,09 \%$ & $0,38 \%$ & $-0,65 \%$ & 592,60 & 5,46 \\
\hline & Urucuia & 13.604 & 6.165 & 7.439 & $54,7 \%$ & $3,53 \%$ & $3,62 \%$ & $3,46 \%$ & $2.082,80$ & 6,53 \\
\hline \multicolumn{2}{|c|}{ Total Vale do Urucuia } & 95.916 & 54.158 & 41.758 & $43,5 \%$ & $1,21 \%$ & $1,98 \%$ & $0,29 \%$ & $25.795,30$ & 3,72 \\
\hline \multirow{10}{*}{$\begin{array}{l}\text { Vale do } \\
\text { Paracatu }\end{array}$} & Brasilândia de Minas & 14.226 & 12.372 & 1.854 & $13,0 \%$ & $2,17 \%$ & $2,99 \%$ & $-1,97 \%$ & $2.523,70$ & 5,64 \\
\hline & Guarda-Mor & 6.565 & 3.688 & 2.877 & $43,8 \%$ & $-0,14 \%$ & $0,49 \%$ & $-0,88 \%$ & $2.072,30$ & 3,17 \\
\hline & João Pinheiro & 45.260 & 36.761 & 8.499 & $18,8 \%$ & $0,90 \%$ & $1,26 \%$ & $-0,51 \%$ & $10.768,40$ & 4,20 \\
\hline & Lagamar & 7.600 & 5.128 & 2.472 & $32,5 \%$ & $-0,14 \%$ & $0,64 \%$ & $-1,58 \%$ & $1.479,70$ & 5,14 \\
\hline & Lagoa Grande & 8.631 & 6.408 & 2.223 & $25,8 \%$ & $1,27 \%$ & $1,58 \%$ & $0,43 \%$ & $1.223,10$ & 7,06 \\
\hline & Paracatu & 84.718 & 73.772 & 10.946 & $12,9 \%$ & $1,20 \%$ & $1,59 \%$ & $-1,08 \%$ & $8.241,10$ & 10,28 \\
\hline & Presidente Olegário & 18.577 & 13.150 & 5.427 & $29,2 \%$ & $0,44 \%$ & $1,71 \%$ & $-2,06 \%$ & $3.539,00$ & 5,25 \\
\hline & São Gonçalo do Abaeté & 6.264 & 4.168 & 2.096 & $33,5 \%$ & $1,44 \%$ & $0,68 \%$ & $3,15 \%$ & $2.695,90$ & 2,32 \\
\hline & Varjão de Minas & 6.054 & 5.021 & 1.033 & $17,1 \%$ & $2,56 \%$ & $3,71 \%$ & $-1,59 \%$ & 654,80 & 9,25 \\
\hline & Vazante & 19.723 & 15.919 & 3.804 & $19,3 \%$ & $0,41 \%$ & $0,64 \%$ & $-0,50 \%$ & $1.913,00$ & 10,31 \\
\hline \multicolumn{2}{|c|}{ Total Vale do Paracatu } & 217.618 & 176.387 & 41.231 & $18,9 \%$ & $1,01 \%$ & $1,51 \%$ & $-0,87 \%$ & $35.111,00$ & 6,20 \\
\hline \multirow{2}{*}{\multicolumn{2}{|c|}{$\begin{array}{l}\text { Total Território } \\
\text { Minas Gerais }\end{array}$}} & 313.534 & 230.545 & 82.989 & $26,5 \%$ & $1,07 \%$ & $1,62 \%$ & $-0,30 \%$ & $60.906,30$ & 5,15 \\
\hline & & 19.597 .330 & 16.715 .216 & 2.882 .114 & $14,7 \%$ & $0,91 \%$ & $1,31 \%$ & $-1,10 \%$ & $588.383,60$ & 33,31 \\
\hline
\end{tabular}

Fonte: Atlas do Desenvolvimento Humano 2013 e IBGE. Dados tabulados pelos autores.

Embora o conjunto de municípios apresente taxa anual de crescimento populacional de 1,21\%, seis municípios apresentaram taxa negativa entre 2000 e 2010 para o total de sua população, enquanto nove municípios apresentaram taxa de crescimento negativa para a população rural. Porém, conforme pode ser observado na Tabela 1, apenas um município (Bonfinópolis de Minas) teve taxa de crescimento negativa para a população urbana. De forma geral, tais dados indicam que continua o processo de êxodo rural, com migração da zona rural para as sedes municipais e também para os municípios polo da região.

Enquanto o Vale do Paracatu reúne dez municípios com população diferenciada, de um lado está Paracatu com 84.718 habitantes e João Pinheiro com 45.260 habitantes, em seguida aparecem três municípios com população entre $14 \mathrm{mil}$ e 20 mil habitantes e cinco com população entre seis e nove mil habitantes. Assim, embora possua 41.233 habitantes no meio rural, a participação sobre a população total é bem menor, 18,9\%. Esse recorte reúne municípios com grandes dimensões, como João Pinheiro $\left(10.768,49 \mathrm{~km}^{2}\right)$, o maior município mineiro, o que resulta em baixa densidade demográfica, apenas 6,20 habitantes por $\mathrm{km}^{2}$. São $35.111 \mathrm{~km}^{2}$ para 217.618 habitantes. 
Os dez municípios em conjunto mantiveram taxa anual de crescimento populacional de $1,01 \%$, sendo que apenas dois municípios apresentaram pequena taxa negativa entre 2000 e 2010 para o total de sua população (Guarda-Mor e Lagamar), enquanto oito municípios apresentaram taxa de crescimento negativa para a população rural. E todos os municípios apresentaram taxa de crescimento positiva para a população urbana, o que também indica contínuo processo de êxodo rural.

A Tabela 2 apresenta um conjunto de dados socioeconômicos que comprova sua evolução entre 2000 e 2010 . Porém, com valores bem inferiores à média mineira e distinto entre os dois grupos de municípios. No grupo de municípios do Vale do Urucuia, o Índice de Desenvolvimento Humano - IDH parte de 0,594 em Pintópolis a 0,678 em Bonfinópolis de Minas, isto para 2010, enquanto o grupo de municípios do Vale do Paracatu parte de 0,670 em São Gonçalo do Abaeté a 0,744 em Paracatu. Nesse conjunto de municípios, o patamar médio é mais elevado e cinco municípios possuem IDH acima de 0,700, considerado alto, sendo que dois deles superam a média mineira em $2010(0,731)$.

Um fato relevante é o comportamento do IDH entre os municípios com piores indicadores, o que vem melhorando acima do ritmo do estado, especialmente, para os municípios do Vale do Urucuia. Enquanto o IDH mineiro cresceu $17 \%$ entre 2000 e 2010 , a média do território foi de $22 \%$ e a média dos municípios do Vale do Urucuia atingiu $27 \%$, sendo que os munícipios de Urucuia, Pintópolis, Chapada Gaúcha e Uruana de Minas cresceram acima de $30 \%$.

Ainda de acordo com a análise dos resultados da Tabela 2, podese concluir pela existência de dois blocos distintos de municípios no Território Noroeste de Minas. No primeiro bloco, estão os municípios do Vale do Urucuia, com renda média per capita variando de apenas $\mathrm{R} \$$ 259,38 em Urucuia a R\$472,14 em Bonfinópolis de Minas, cuja média foi de $R \$ 325,76$. Enquanto no Vale do Paracatu a renda média foi de $R \$$ 591,29, com a menor renda per capita obtida em Brasilândia de Minas $(R \$ 444,35)$ e Guarda Mor com a maior renda ( $R \$ 669,72)$, inferior à média mineira que foi de $R \$ 749,69$. 
Tabela 2. Dados socioeconômicos dos municípios do Território Noroeste de Minas

\begin{tabular}{|c|c|c|c|c|c|c|c|c|c|}
\hline & \multirow[t]{2}{*}{ Municípios/Anos } & \multicolumn{2}{|c|}{ IDHM } & \multicolumn{2}{|c|}{\begin{tabular}{|c|} 
Renda per capita \\
$(\mathbf{R} \$)$
\end{tabular}} & \multicolumn{2}{|c|}{$\begin{array}{c}\text { \% de extrem. } \\
\text { pobres }\end{array}$} & \multicolumn{2}{|c|}{$\%$ de pobres } \\
\hline & & 2000 & 2010 & 2000 & 2010 & 2000 & 2010 & 2000 & 2010 \\
\hline \multirow{12}{*}{$\begin{array}{l}\text { Vale do } \\
\text { Urucuia }\end{array}$} & Urucuia & 0,459 & 0,619 & 173,98 & 259,38 & 38,83 & 12,86 & 66,58 & 35,63 \\
\hline & Pintópolis & 0,451 & 0,594 & 144,94 & 260,14 & 43,58 & 24,76 & 64,43 & 41,84 \\
\hline & Chapada Gaúcha & 0,484 & 0,635 & 253,67 & 282,53 & 38,54 & 20,16 & 65,39 & 35,32 \\
\hline & Riachinho & 0,513 & 0,632 & 206,93 & 290,89 & 32,33 & 16,98 & 58,36 & 33,66 \\
\hline & São Romão & 0,518 & 0,640 & 213,48 & 307,02 & 31,81 & 14,20 & 63,34 & 35,65 \\
\hline & Santa Fé de Minas & 0,516 & 0,615 & 196,31 & 313,25 & 27,98 & 16,05 & 61,50 & 32,46 \\
\hline & Arinos & 0,514 & 0,656 & 242,04 & 349,52 & 33,86 & 15,34 & 57,05 & 35,37 \\
\hline & Uruana de Minas & 0,477 & 0,664 & 168,52 & 360,58 & 28,30 & 15,36 & 48,55 & 28,09 \\
\hline & Formoso & 0,503 & 0,640 & 311,16 & 370,41 & 32,50 & 13,71 & 52,80 & 30,59 \\
\hline & Dom Bosco & 0,538 & 0,673 & 251,40 & 394,72 & 17,20 & 5,31 & 44,26 & 18,86 \\
\hline & Natalândia & 0,546 & 0,671 & 285,13 & 431,11 & 19,14 & 3,62 & 41,87 & 13,40 \\
\hline & Bonfinópolis de Minas & 0,567 & 0,678 & 311,58 & 472,15 & 15,87 & 4,75 & 43,45 & 14,32 \\
\hline \multicolumn{2}{|c|}{ Total Vale do Urucuia } & 0,505 & 0,640 & 229,11 & 325,76 & 31,95 & 14,70 & 57,48 & 32,31 \\
\hline \multirow{10}{*}{$\begin{array}{l}\text { Vale do } \\
\text { Paracatu }\end{array}$} & Brasilândia de Minas & 0,564 & 0,674 & 380,15 & 444,35 & 15,52 & 3,04 & 40,31 & 13,40 \\
\hline & São Gonçalo do Abaeté & 0,553 & 0,670 & 354,44 & 502,57 & 7,95 & 5,32 & 30,96 & 12,42 \\
\hline & Varjão de Minas & 0,583 & 0,711 & 343,98 & 528,14 & 4,29 & 3,37 & 20,24 & 7,68 \\
\hline & Lagoa Grande & 0,571 & 0,679 & 375,81 & 543,58 & 6,39 & 2,53 & 24,86 & 12,74 \\
\hline & Presidente Olegário & 0,557 & 0,701 & 349,69 & 546,68 & 9,43 & 3,67 & 25,02 & 9,80 \\
\hline & João Pinheiro & 0,581 & 0,697 & 387,79 & 562,24 & 8,75 & 3,28 & 29,92 & 12,24 \\
\hline & Lagamar & 0,610 & 0,718 & 360,19 & 592,95 & 8,58 & 3,42 & 25,16 & 9,36 \\
\hline & Paracatu & 0,613 & 0,744 & 443,35 & 637,80 & 8,64 & 2,37 & 28,15 & 9,34 \\
\hline & Vazante & 0,619 & 0,742 & 509,74 & 650,88 & 3,78 & 2,49 & 17,88 & 5,39 \\
\hline & Guarda-Mor & 0,580 & 0,690 & 443,52 & 660,72 & 4,83 & 3,30 & 17,55 & 10,15 \\
\hline \multicolumn{2}{|c|}{ Total Vale do Paracatu } & 0,594 & 0,718 & 415,23 & 591,29 & 8,33 & 2,91 & 27,25 & 10,09 \\
\hline \multicolumn{2}{|r|}{ Indicador Territorial } & 0,567 & 0,694 & 359,07 & 510,06 & 15,45 & 6,52 & 36,37 & 16,89 \\
\hline \multicolumn{2}{|r|}{ Minas Gerais } & 0,624 & 0,731 & 548,87 & 749,69 & 9,05 & 3,49 & 24,64 & 10,97 \\
\hline
\end{tabular}

Fonte: Atlas do Desenvolvimento Humano no Brasil (2013). Dados tabulados pelos autores.

Sendo assim, embora haja significativo avanço na renda dos municípios mais pobres entre 2000 e 2010 , o que pode ser observado é que o percentual de extremamente pobres nos municípios do Vale do Urucuia é de $14,70 \%$ da população e o percentual de pobres é de $32,31 \%$, cujos percentuais são bem menores nos municípios do Vale do Paracatu - 2,91\% para extremamente pobres e 10,09\% para pobres. Nesse caso, os percentuais são inferiores à media do estado, respectivamente $3,49 \%$ e 10,97\%. De acordo com Jesus e Ortega (2014), a queda nesses percentuais, especialmente nos municípios mais empobrecidos, se deve em grande medida ao programa Bolsa Família do governo federal. 
Para melhor caracterizar esses municípios, foram utilizadas informações sobre suas atividades econômicas por meio do Valor Agregado Bruto - VAB e do Produto Interno Bruto - PIB, o que configura duas regiões distintas. Considerando a participação do VAB por setores em 2010, enquanto o estado possui $8,48 \%$ no setor agropecuário, $33,58 \%$ no industrial e $57,94 \%$ no setor de serviços, dos quais $13,41 \%$ provêm do setor público, nos municípios do Vale do Urucuia pode-se observar que há elevada participação setor agropecuário $(37,64 \%)$, baixa participação do setor industrial (8,29\%) e no setor de serviços $(54,07 \%)$, dos quais pouco mais da metade vem do setor público $(27,94 \%)$. No Vale do Paracatu, o setor agropecuário representa 31,89\%, o setor industrial $(27,45 \%)$ e o setor de serviços de $40,66 \%$, dos quais apenas $12,78 \%$ vêm do setor público (Tabela 3 ).

Tabela 3. Participação do Valor Agregado Bruto a Preços Correntes por setor de atividade e taxa de crescimento do PIB nos municípios do

Noroeste de Minas

\begin{tabular}{|c|c|c|c|c|c|c|c|}
\hline \multicolumn{2}{|r|}{ Municípios/Ano } & $\begin{array}{c}\text { VAB } \\
\text { Agropecuária }\end{array}$ & $\begin{array}{c}\text { VAB } \\
\text { Indústria }\end{array}$ & $\begin{array}{c}\text { VAB } \\
\text { Serviços }\end{array}$ & $\begin{array}{c}\text { VAB Serviços } \\
\text { Adm. }\end{array}$ & $\begin{array}{l}\text { VAB Total (Mil } \\
\text { Reais) }\end{array}$ & $\begin{array}{l}\text { Taxa anual de } \\
\text { Crescimento }\end{array}$ \\
\hline & & 2010 & 2010 & 2010 & 2010 & 2010 & $2000-2010$ \\
\hline \multirow{12}{*}{$\begin{array}{l}\text { Vale do } \\
\text { Urucuia }\end{array}$} & Arinos & $36,48 \%$ & $9,03 \%$ & $54,49 \%$ & $26,04 \%$ & 134.790 & $3,95 \%$ \\
\hline & Bonfinópolis de Minas & $54,11 \%$ & $5,42 \%$ & $40,47 \%$ & $14,80 \%$ & 91.628 & $3,06 \%$ \\
\hline & Uruana de Minas & $37,13 \%$ & $9,91 \%$ & $52,96 \%$ & $31,71 \%$ & 27.528 & $-0,56 \%$ \\
\hline & Chapada Gaúcha & $34,59 \%$ & $9,08 \%$ & $56,33 \%$ & $33,16 \%$ & 63.453 & $3,49 \%$ \\
\hline & Dom Bosco & $50,72 \%$ & $5,63 \%$ & $43,65 \%$ & $20,81 \%$ & 41.422 & $2,82 \%$ \\
\hline & Formoso & $45,25 \%$ & $5,84 \%$ & $48,91 \%$ & $18,94 \%$ & 91.421 & $3,60 \%$ \\
\hline & Santa Fé de Minas & $30,48 \%$ & $8,79 \%$ & $60,72 \%$ & $36,90 \%$ & 25.138 & $4,99 \%$ \\
\hline & Riachinho & $31,40 \%$ & $8,23 \%$ & $60,37 \%$ & $30,63 \%$ & 53.342 & $4,36 \%$ \\
\hline & São Romão & $24,21 \%$ & $11,23 \%$ & $64,55 \%$ & $36,30 \%$ & 56.271 & $6,50 \%$ \\
\hline & Pintópolis & $22,81 \%$ & $10,27 \%$ & $66,92 \%$ & $41,68 \%$ & 35.301 & $4,51 \%$ \\
\hline & Natalândia & $35,05 \%$ & $7,04 \%$ & $57,90 \%$ & $34,36 \%$ & 25.084 & $4,37 \%$ \\
\hline & Urucuia & $30,09 \%$ & $10,99 \%$ & $58,92 \%$ & $37,43 \%$ & 69.332 & $6,73 \%$ \\
\hline \multicolumn{2}{|c|}{ Total Vale do Urucuia } & $37,64 \%$ & $8,29 \%$ & $54,07 \%$ & $27,94 \%$ & 714.710 & $3,96 \%$ \\
\hline \multirow{10}{*}{$\begin{array}{l}\text { Vale do } \\
\text { Paracatu }\end{array}$} & João Pinheiro & $39,09 \%$ & $15,95 \%$ & $44,96 \%$ & $14,29 \%$ & 664.143 & $7,84 \%$ \\
\hline & Presidente Olegário & $53,40 \%$ & $6,26 \%$ & $40,33 \%$ & $15,69 \%$ & 249.254 & $1,95 \%$ \\
\hline & Guarda-Mor & $72,39 \%$ & $4,06 \%$ & $23,55 \%$ & $7,41 \%$ & 217.753 & $6,41 \%$ \\
\hline & Lagamar & $33,81 \%$ & $24,81 \%$ & $41,38 \%$ & $16,65 \%$ & 93.702 & $2,13 \%$ \\
\hline & São Gonçalo do Abaeté & $39,59 \%$ & $10,14 \%$ & $50,27 \%$ & $16,05 \%$ & 95.916 & $6,02 \%$ \\
\hline & Paracatu & $19,86 \%$ & $39,29 \%$ & $40,85 \%$ & $11,27 \%$ & 1.624 .360 & $6,30 \%$ \\
\hline & Brasilândia de Minas & $35,40 \%$ & $10,93 \%$ & $53,66 \%$ & $21,61 \%$ & 127.849 & $1,43 \%$ \\
\hline & Lagoa Grande & $50,30 \%$ & $13,57 \%$ & $36,13 \%$ & $14,26 \%$ & 121.754 & $6,25 \%$ \\
\hline & Varjão de Minas & $52,29 \%$ & $11,84 \%$ & $35,87 \%$ & $15,04 \%$ & 84.236 & $2,68 \%$ \\
\hline & Vazante & $18,87 \%$ & $43,40 \%$ & $37,72 \%$ & $11,97 \%$ & 364.895 & $5,68 \%$ \\
\hline \multicolumn{2}{|c|}{ Total Vale do Paracatu } & $31,89 \%$ & $27,45 \%$ & $40,66 \%$ & $12,78 \%$ & 3.643 .862 & $5,69 \%$ \\
\hline & Noroeste de Minas & $32,83 \%$ & $24,31 \%$ & $42,86 \%$ & $15,26 \%$ & 4.358 .572 & $5,39 \%$ \\
\hline & Minas Gerais & $8,48 \%$ & $33,58 \%$ & $57,94 \%$ & $13,41 \%$ & 307.864 .864 & $4,53 \%$ \\
\hline & Brasil & $5,30 \%$ & $28,07 \%$ & $66,63 \%$ & $16,20 \%$ & 3.227.180.667 & $3,61 \%$ \\
\hline
\end{tabular}

Fonte: IBGE. Dados tabulados pelos autores. 
Esses dados devem ser analisados em conjunto com o montante do $V A B$, pois as duas regiões apresentam dinâmicas distintas. De um lado, os 12 municípios do Vale do Urucuia responderam por apenas 16,4\% dos 4,358 bilhões de reais de VAB do Território em 2010, equivalente a 714,7 milhões de reais, enquanto a sua população representava $30,6 \%$. Os 714,7 milhões de reais de $V A B$ estão relativamente distribuídos pelo conjunto de municípios, (são municípios que têm elevada participação da agricultura familiar de pequeno porte, possuem grande parte de suas terras em baixas altitudes, enfrentam problemas de secas mais severas e possuem poucas áreas de chapadas para a produção agropecuária, cuja atividade de destaque é o gado de corte que agrega pouco valor e a produção para o autoconsumo). Justamente os municípios que possuem terras no alto das chapadas são aqueles que se destacam na geração do $V A B$ na região - Arinos, Bonfinópolis de Minas, Formoso e Urucuia, os quais representam $54 \%$ do VAB dos 12 municípios.

Enquanto isso, a atividade econômica no Vale do Paracatu é mais diversificada entre os municípios. Todos possuem produção importante na atividade agropecuária, em grande medida por possuírem grandes chapadas propícias à produção de grãos, com destaque para os municípios Guarda-Mor, Presidente Olegário, Paracatu, Varjão de Minas e São Gonçalo do Abaeté, sendo que três desses se destacam, também, na produção de café; Lagoa Grande, Lagamar e Vazante se destacam na produção de leite e João Pinheiro destaca-se na produção de carvão vegetal. $\mathrm{Na}$ atividade de transformação, há que se destacar a atividade de extração mineral (ouro, calcário, zinco, entre outros minerais) em Paracatu, Lagamar e Vazante, com presença de importantes grupos empresariais nacionais. O setor de serviços tem baixa participação média de $40,66 \%$ para os municípios.

Em função dessa diversidade, o conjunto de municípios do Vale do Paracatu apresentou melhores resultados econômicos em relação aos municípios do Vale do Urucuia, concentrando $83,6 \%$ da VAB do Território Noroeste de Minas. Dentre os dez municípios, em função do peso populacional e das atividades econômicas, diferentemente do Vale Urucuia, há uma grande contração de atividades econômicas em poucos municípios: Paracatu com 44,6\% do VAB da região, João Pinheiro com 
$18,2 \%$ e Vazante com $10 \%$, com concentração do VAB da ordem de $73 \%$ nesses três municípios.

No conjunto, tomando como parâmetro os dados da Tabela 3, pode-se caracterizar que os municípios rurais menos dinâmicos em relação ao comportamento do $V A B$ são os que possuem significativa participação no setor agropecuário, baixa participação da indústria e maior participação do setor de serviços, com grande peso dos serviços administrados, como pode ser exemplificado pelos municípios do Vale do Urucuia. Situação distinta dos municípios mais dinâmicos do Vale do Paracatu (Paracatu, João Pinheiro e Vazante).

Por fim, pode-se observar que a dinâmica econômica entre os dois grupos de municípios é bem diferenciada. Enquanto os municípios do Vale do Urucuia mantiveram uma trajetória de crescimento do PIB anual de 3,96\%, entre 2000 e 2010, Minas Gerais cresceu 4,53\%. Já o Vale do Paracatu cresceu a uma taxa anual de $5,69 \%$, o que demonstra que as diferenças econômicas entre as duas regiões vem aumentando, ao invés de diminuir, uma vez que o território é fruto de uma política de desenvolvimento.

\section{Considerações finais}

Este artigo buscou contribuir para o debate acerca do desenvolvimento territorial ao defender que a formulação das políticas de desenvolvimento precisam considerar a articulação funcional dos municípios que são agrupados para a formação do território. Este, enquanto um recorte espacial para a definição e implementação de políticas públicas, é algo construído institucionalmente e sua delimitação precisa considerar quais são as redes de influência sobre os municípios, quais são os sistemas produtivos ali existentes, quais são as direções e os sentidos dos fluxos que se estabelecem entre os municípios e destes com aqueles que estão fora do recorte territorial. Ou seja, identificar quais são os principais municípios que polarizam e exercem influência sobre as cidades do território consiste em um indicador para verificar se há articulação e coesão entre eles.

As informações levantadas durante a pesquisa realizada no Território Noroeste de Minas permitiram identificar dificuldades tais como: longos deslocamentos, rodovias não pavimentadas, poucas 
ligações entre os municípios e fluxos econômicos e de pessoas divergentes dentre os municípios. Portanto, inviabiliza-se a definição de quais são os projetos prioritários e decisões acerca da utilização dos recursos públicos. Uma das explicações para a dificuldade da cencertação de interesses (convergir para um projeto comum) que foi possível identificar consiste na dimensão do território que articula diferentes sistemas sócio produtivos, municípios que sofrem distintas influências dentro da rede urbana nacional e que, por sua vez, estabelecem fluxos diários que não convergem para o conjunto do território. Dessa forma, esses elementos evidenciam a baixa articulação funcional entre os municípios que oficialmente formam o território. Interessante notar que a delimitação do território não coincide nem mesmo com os recortes de atuação de órgãos públicos estaduais e federais.

Por conseguinte, ao analisar o Território Noroeste de Minas, verifica-se que esse recorte territorial feito de forma imposta não foi capaz de engendrar um projeto comum de desenvolvimento. O recorte territorial concebido no formato de 22 municípios não se consolidou passado mais de uma década de sua criação (2003), apontando que não foi possível aglutinar representantes do poder público e da sociedade civil de todos os municípios que conformam o território. Na verdade, apenas pouco mais da metade dos representantes dos municípios participam ativamente e apontam que os membros do Colegiado não conseguiram identificar uma "Ideia Guia" e apresenta dificuldades para elaborar um projeto conjunto (comum) cuja identidade caracterize um território.

Essas informações corroboram os resultados apresentados neste artigo. Mostrou-se, neste trabalho, que os municípios estão sob três redes de influências distintas que não se comunicam, pois apresentam direção dos fluxos que extrapolam a delimitação do território. Ao mesmo tempo, os dados populacionais, socioeconômicos e produtivos demostram existir dois subterritórios com dinâmicas diferenciadas e demandas distintas por políticas públicas. Eles se diferenciam por estarem polarizados por diferentes municípios, sendo que o Vale do Paracatu está sob influência de Patos de Minas, e o Vale do Urucuia tem duas influências distintas, Unaí e Brasília de um lado, Montes Claros e Belo Horizonte por outro lado. Assim, uma possibilidade de viabilizar a 
política de desenvolvimento territorial seria a divisão do Território. De um lado, ficariam os municípios do vale do Paracatu, que envolve dez municípios, nove deles são os mesmos que estão na área de influência de Patos de Minas, mais a inclusão de Paracatu, que se justifica pelas características socioeconômicas parecidas com as dos demais municípios.

De outro lado, estaria o Vale do Urucuia, com 12 municípios que reúnem características populacionais, socioeconômicas e produtivas relativamente mais próximas, o que facilitaria para criarem um projeto comum. Entretanto, essa subdivisão territorial pode não funcionar na totalidade, pois uma parte dos municípios está ligada ao Norte de Minas, a Montes Claros, especialmente Pintópolis e São Romão, e o outro conjunto está sob influência de Unaí e Brasília. Portanto, há dois grupos de municípios com polarizações distintas. Ademais, em virtude das características do município de Unaí, da articulação funcional que ele tem com parte dos municípios do Vale do Urucuia, uma proposta seria incluir esse município em um território que contemplasse os municípios que estão dentro do seu raio de influência. Portanto, desses 12 municípios poderiam ser criados mais dois territórios: um, com os municípios que estão sob influência de Unaí e outro, sob influência de Montes Claros. É possível, inclusive, a incorporação de outros municípios, que não fazem parte do Território Noroeste de Minas, que estejam sob essas áreas de influência e que tenham condições socioeconômicas comuns.

Portanto, a contribuição deste artigo é de identificar que, além daqueles já estabelecidos pelos programas de desenvolvimento territorial, outros critérios devem ser incorporados à definição das políticas territoriais para que se crie um ambiente em que sejam mais claras as prioridades da sociedade e viabilize sua participação na formulação das políticas públicas:

a) Necessidade de estudo prévio acerca de quais são as polarizações incidentes sobre os municípios que formarão o território de modo a identificar como se estrutura suas redes de influência;

b) Qual é o raio de atuação de órgãos estaduais e federais que se estruturam regionalmente;

c) Qual é o perfil socioeconômico dos municípios;

d) Qual é o tamanho e o número máximo de municipios; 
e) Como se configuram os sistemas produtivos municipais.

A tentativa de confluir ao máximo esses critérios poderá levar à criação de recortes institucionais dentro da perspectiva do desenvolvimento territorial rural que contribuam para uma melhor identificação das demandas territoriais, dentro de uma perspectiva de que essas ações de políticas públicas não podem estar desarticuladas do desenvolvimento regional e este, por sua vez, deve estar articulado ao desenvolvimento nacional, enfatizando que se trata de uma política intermunicipal e multiescalar, e de forma alguma localizada e atomizada.

\section{REFERÊNCIAS}

ATLAS BRASIL 2013. Atlas do Desenvolvimento Humano no Brasil 2013. Realização: PNUD, IPEA e FJP. Disponível em: <http://atlasbrasil.org.br/2013/pt/>. Acesso em: 13 jan. 2014.

BRANDÃO, Carlos Antônio. Território e Desenvolvimento. As múltiplas escalas entre o local e o global. Campinas: Editora Unicamp, 2007.

ECHEVERRI, Rafael. Emergência e evolução do programa de desenvolvimento sustentável dos territórios rurais e nos territórios da cidadania. In MIRANDA, C.; TRIBURCIO, B. Políticas de Desenvolvimento Territorial Rural no Brasil: avanços e desafios. Série Desenvolvimento Territorial Sustentável. Volume 12. Brasília: IICA, p. 81-114, 2010.

EMATER. Empresa de Assistência Técnica e Extensão Rural do Estado de Minas Gerais. Disponível em <http://www.emater.mg.gov.br>. Acesso em: jan. 2014.

FERNANDES FILHO, J. F.; JESUS, C. M.; CARDOZO, S. A. Análise da Estrutura Social e Econômica Relacionada ao Desenvolvimento da Agricultura Familiar no Território Rural Noroeste de Minas. Relatório Analítico Edital MDA/SDT/CNPq - Gestão de Territórios Rurais $\mathrm{N}^{\circ}$. 05/2009. Uberlândia, 2014.

GUIA RODOVIÁRIO. Guia Quatro Rodas. São Paulo: Ed. Abril, 2010. 
GUIMARÃES NETO, Leonardo. Evolução e antecedentes do planejamento territorial no Brasil. In MIRANDA, C.; TRIBURCIO, B. Políticas de Desenvolvimento Territorial Rural no Brasil: avanços e desafios. Série Desenvolvimento Territorial Sustentável. Volume 12. Brasília: IICA, p. 47-79, 2010.

IBGE - INSTITUTO BRASILEIRO DE GEOGRAFIA E eSTATÍ́stICA. Censo Demográfico 2000. Disponível em <http://www.ibge.gov.br>. Acesso em 2014a.

----_. Censo Demográfico 2010. Disponível em: <http://www.ibge.gov.br>. Acesso em 2014b.

IPEA; IBGE; UNICAMP. Caracterização e tendências da rede urbana do Brasil: configurações atuais e tendências da rede urbana. Sudeste. Brasília: IPEA, 2001.

JESUS, Clesio Marcelino. Desenvolvimento Territorial Rural: análise comparada entre os territórios constituídos autonomamente e os induzidos pelas políticas públicas no Brasil e na Espanha. 2013. 287 p. Tese (Programa de Pós-Graduação em Economia - Mestrado e Doutorado) - Universidade Federal de Uberlândia, Uberlândia. 2013.

JESUS, C. M.; ORTEGA, A. C. O desenvolvimento territorial rural em minas gerais: resultados de uma década de políticas governamentais. In: SEMINÁRIOS DA SOCIEDADE BRASILEIRA DE ECONOMIA, ADMINISTRAÇÃO E SOCIOLOGIA RURAL 2014, Goiânia. Anais... Goiânia: SOBER, p. 1-20, 2014.

MOTTA, D. M.; AJARA, C. Configuração da rede urbana do Brasil. Revista Paranaense de Desenvolvimento, n. 100. Curitiba: IPARDES, janeirojunho, 2001.

ORTEGA, Antonio César. Territórios Deprimidos. Campinas, SP: Alínea; Uberlândia, MG: EDUFU, 2008. 
PTDRS. Plano Territorial de Desenvolvimento Rural Sustentável: Território da Cidadania Noroeste de Minas. Minas Gerais, Colegiado Territorial/APTA/SDT/MDA - nov. de 2010.

REGIC. Região de Influências das Cidades 2007. Rio de Janeiro, IBGE, 2008.

SANTOS, Milton. O Brasil: território e sociedade no início do século XXI. Rio de Janeiro: Record, 2001.

SDT/MDA (Secretaria de Desenvolvimento Territorial/ Ministério do Desenvolvimento Agrário) Colegiados Territoriais: Guia para a organização social dos territórios. Documento de apoio 05. Brasília, 2010.

VEIGA, José Eli. Cidades imaginárias. O Brasil é menos urbano do que se calcula. Campinas: Autores Associados, 2002, 304p.

Submetido em 24/02/2015

Aprovado em 17/03/2016

\section{Sobre os autores}

Clesio Marcelino de Jesus

Doutor em Economia pela Universidade Federal de Uberlândia. Professor Adjunto 1 do Instituto de Economia da Universidade Federal de Uberlândia (IEUFU). E-mail: clesiomj@ie.ufu.br.

\section{Soraia Aparecida Cardozo}

Doutora em Desenvolvimento Econômico pela Universidade Estadual de Campinas (UNICAMP). Professora Adjunta 3, Instituto de Economia da Universidade Federal de Uberlândia (IEUFU).E-mail: soraiacar@ie.ufu.br. 


\section{ANEXO}

\section{Matriz de pessoas ocupadas no Território Noroeste de Minas (total e percentual em deslocamento no território e} para os dois principais destinos fora do território em 2010)

\begin{tabular}{|c|c|c|c|c|c|c|c|c|c|c|c|c|c|c|c|c|c|c|c|c|c|c|c|c|c|c|c|c|c|}
\hline \multirow[b]{2}{*}{ Número } & \multirow{2}{*}{$\begin{array}{l}\text { Municípios do } \\
\text { Território }\end{array}$} & \multicolumn{2}{|c|}{ Pessoas Ocupadas } & \multicolumn{22}{|c|}{ Município de destino dos deslocamentos dentro do Território Noroeste de Minas (\%) } & \multicolumn{4}{|c|}{ Outros municípios } \\
\hline & & Total & \begin{tabular}{|c|}
$(\%)$ em \\
deslocamento
\end{tabular} & 1 & 2 & 3 & 4 & 5 & 6 & 7 & 8 & 9 & 10 & 11 & 12 & 13 & 14 & 15 & 16 & 17 & 18 & 19 & 20 & 21 & 22 & Município & $\%$ & Município & $\%$ \\
\hline & 1 Arinos & 7.301 & 2,67 & & 0,00 & 0,10 & 0,00 & 0,06 & 0,00 & 0,06 & 0,12 & 0,09 & 0,26 & 0,00 & 0,000 & 0,000 & 0,00 & 0,00 & $0,00 \mathrm{C}$ & 0,000 & 0,00 & 0,000 & 0,00 & 0,00 & 0,00 & Brasília & & Cristalina & 0,2 \\
\hline & 2 Bonfinópolis de Minas & 2.467 & 4,60 & 0,00 & & 0,90 & 0,12 & 0,00 & 0,17 & 0,16 & 0,14 & 0,14 & 0,00 & 0,00 & 0,080 & 0,250 & 0,00 & 0,14 & $0,00 \mathrm{C}$ & 0,000 & 0,28 & 0,000 & 0,00 & 0,00 & 0,00 & Brasilia & & Nova Serrana & 0,2 \\
\hline & 3 Brasilândia de Minas & 6.395 & 9,22 & 0,00 & 0,18 & & 0,17 & 0,00 & 0,00 & 0,16 & 0,09 & 0,08 & 0,00 & 0,00 & 0,250 & 0,000 & 0,00 & 6,44 & $0,00 \mathrm{C}$ & 0,000 & 0,53 & 0,000 & 0,00 & 0,00 & 0,00 & Unaí & & Belo Horizonte & 0,3 \\
\hline & 4 Dom Bosco & 1.768 & 7,70 & 0,00 & 1,07 & 1,33 & & 0,15 & 0,00 & 0,00 & 0,00 & 0,00 & 0,00 & 0,00 & 0,000 & 0,000 & 0,00 & 0,50 & $0,00 \mathrm{C}$ & 0,000 & 0,91 & 0,000 & 0,00 & 0,00 & 0,00 & Unaí & & Brasília & 0,9 \\
\hline & 5 Formoso & 3.436 & 9,70 & 0,00 & 0,00 & 0,00 & 0,00 & & 0,00 & 0,00 & 0,00 & 0,00 & 0,12 & 0,00 & 0,000 & 0,000 & 0,00 & 0,00 & $0,00 \mathrm{C}$ & 0,000 & 0,23 & $0,00 \mathrm{C}$ & 0,00 & 0,00 & 0,00 & Brasília & & Formosa & 0,9 \\
\hline & 6 Natalândia & 1.550 & 11,31 & 0,00 & 2,87 & 0,53 & 0,38 & 0,00 & . & 0,00 & 0,00 & 0,00 & 0,00 & 0,00 & 0,000 & 0,000 & 0,00 & 0,33 & $0,00 \mathrm{C}$ & 0,000 & 0,59 & $0,00 \mathrm{C}$ & 0,00 & 0,00 & 0,00 & Unaí & & Brasília & 0,3 \\
\hline & 7 Riachinho & 3.153 & 5,90 & 0,90 & 0,00 & 1,36 & 0,00 & 0,00 & 0,00 & & 0,36 & 0,29 & 0,00 & 0,00 & 0,380 & 0,000 & 0,00 & 0,00 & $0,00 \mathrm{C}$ & 0,000 & 0,00 & $0,00 \mathrm{C}$ & 0,00 & 0,00 & 0,00 & Brasília & & Unaí & 0,8 \\
\hline & 8 Uruana de Minas & 1.227 & 10,98 & 1,00 & 2,70 & 0,00 & 0,00 & 0,00 & 0,00 & 0,00 & & 0,00 & 0,00 & 0,00 & 0,000 & 0,000 & 0,00 & 0,44 & $0,00 \mathrm{C}$ & 0,000 & 0,34 & $0,00 \mathrm{C}$ & 0,00 & 0,00 & 0,00 & Unaí & & Brasília & 2,0 \\
\hline & 9 Urucuia & 4.862 & 4,61 & 0,15 & 0,20 & 0,18 & 0,00 & 0,00 & 0,00 & 0,20 & 0,00 & & 0,10 & 0,00 & 0,000 & 0,000 & 0,00 & 0,00 & 0,000 & 0,000 & 0,00 & $0,00 \mathrm{C}$ & 0,00 & 0,00 & 0,00 & Brasília & & São Paulo & 0,4 \\
\hline & 0 Chapada Gaúcha & 4.958 & 7,33 & 0,30 & 0,00 & 0,00 & 0,00 & 0,00 & 0,00 & $0,00 \mathrm{C}$ & 0,00 & 0,07 & & 0,11 & 0,000 & 0,000 & 0,00 & 0,23 & $0,00 \mathrm{C}$ & 0,000 & 0,11 & $0,00 \mathrm{C}$ & 0,00 & 0,00 & 0,00 & Brasília & & Januária & 1,1 \\
\hline & 1 Pintópolis & 2.594 & 10,15 & 0,00 & 0,00 & 0,00 & 0,00 & 0,00 & 0,00 & 0,00 & 0,00 & 0,00 & 0,20 & & 0,000 & 0,000 & 0,00 & 0,00 & $0,00 \mathrm{C}$ & 0,000 & 0,00 & $0,16 \mathrm{c}$ & 0,00 & 0,00 & 0,00 & Cristalina & & itards & 1,5 \\
\hline & 2 Santa Fé de Minas & 1.784 & 3,89 & 0,00 & 0,45 & 0,56 & 0,00 & 0,00 & 0,00 & 0,00 & 0,00 & 0,19 & 0,00 & 0,00 & & 0,800 & 0,00 & 0,22 & $0,00 \mathrm{C}$ & 0,000 & 0,00 & $0,00 \mathrm{C}$ & 0,00 & 0,00 & 0,00 & Buritizeiro & & Pirapora & 0,4 \\
\hline & 3 São Romão & 4.513 & 3,58 & 0,00 & 0,00 & 0,00 & 0,00 & 0,00 & 0,00 & 0,00 & 0,00 & 0,00 & 0,00 & 0,16 & 0,25 & & 0,00 & 0,00 & $0,00 \mathrm{C}$ & 0,000 & 0,00 & $0,00 \mathrm{C}$ & 0,00 & 0,00 & 0,00 & Belo Horizonte & & Ubaí & 0,5 \\
\hline & 4 Guarda-Mor & 3.133 & 1,37 & 0,00 & 0,00 & 0,00 & 0,00 & 0,00 & 0,00 & 0,00 & 0,00 & 0,00 & 0,00 & 0,00 & 0,000 & 0,00 & & 0,00 & $0,00 \mathrm{C}$ & 0,000 & 0,16 & $0,00 \mathrm{C}$ & 0,00 & 0,00 & 0,45 & Coromandel & & $\mathrm{Ub}$ & 0,2 \\
\hline & 5 João Pinheiro & 21.104 & 2,67 & 0,00 & 0,05 & 0,10 & 0,00 & 0,00 & 0,00 & 0,00 & 0,00 & 0,00 & 0,00 & 0,00 & 0,000 & 0,000 & 0,00 & & $0,00 \mathrm{C}$ & 0,300 & 0,41 & 0,050 & 0,05 & 0,00 & 0,10 & Brasília & & Horizonte & 0,2 \\
\hline & 6 Lagamar & 3.322 & 7,78 & 0,00 & 0,00 & 0,00 & 0,00 & 0,00 & 0,00 & 0,00 & 0,00 & 0,00 & 0,00 & 0,00 & 0,000 & 0,000 & 0,14 & 0,00 & & 0,000 & 0,32 & $0,91 \mathrm{C}$ & 0,00 & 0,00 & 1,61 & Patos de Minas & & Coromandel & 0,9 \\
\hline & 7 Lagoa Grande & 4.008 & 8,86 & 0,00 & 0,00 & 0,12 & 0,00 & 0,00 & 0,00 & 0,00 & 0,00 & 0,00 & 0,00 & 0,00 & 0,000 & 0,000 & 0,00 & 2,15 & 0,15 & & 0,84 & 2,11 & 0,00 & 0,00 & 0,38 & Patos de Minas & & Coromandel & 0,4 \\
\hline & 8 Paracatu & 39.130 & 2,19 & 0,00 & 0,00 & 0,02 & 0,00 & 0,00 & 0,00 & 0,00 & 0,00 & 0,00 & 0,02 & 0,00 & 0,000 & 0,000 & 0,09 & 0,11 & $0,03 c$ & 0,00 & & 0,00 & 0,00 & 0,00 & 0,08 & Brasília & & Unaí & 0,2 \\
\hline & 9 Presidente Olegário & 8.975 & 6,76 & 0,00 & 0,00 & 0,06 & 0,00 & 0,00 & 0,00 & 0,00 & 0,00 & 0,00 & 0,00 & 0,00 & 0,000 & 0,000 & 0,11 & 0,21 & $0,22 \mathrm{c}$ & 0,300 & 0,33 & 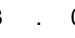 & 0,05 & 0,05 & 0,05 & Patos de Minas & & Patrocínio & 0,3 \\
\hline & 0 São Gonçalo do Abaeté & 2.674 & 12,62 & 0,00 & 0,00 & 0,00 & 0,00 & 0,00 & 0,00 & 0,00 & 0,00 & 0,00 & 0,00 & 0,00 & 0,000 & 0,000 & 0,007 & 7,79 & $0,00 \mathrm{C}$ & 0,000 & 0,00 & 0,00 & & 1,13 & 0,00 & Três Marias & & Patos de Minas & 0,6 \\
\hline & 1 Varjão de Minas & 2.932 & 28,00 & 0,00 & 0,00 & 0,00 & 0,00 & 0,00 & 0,00 & 0,00 & 0,00 & 0,00 & 0,00 & 0,00 & 0,000 & 0,000 & 0,002 & 22,99 & $0,00 \mathrm{C}$ & 0,000 & 0,00 & 1,71 & 1,12 & & 0,00 & Patos de Minas & & Belo Horizonte & 0,2 \\
\hline & 2 Vazante & 9.736 & 5,05 & 0,00 & 0,00 & 0,00 & 0,00 & 0,00 & 0,00 & 0,00 & 0,00 & 0,00 & 0,00 & 0,00 & 0,000 & $0,00 \mathrm{c}$ & 0,92 & 0,00 & $0,34 \mathrm{C}$ & 0,001 & 1,02 & 0,11 & 0,00 & 0,00 & & Uberlândia & & Catalão & 0,4 \\
\hline
\end{tabular}

Fonte: IBGE (2014), com modificações pelos autores. 